\title{
Examination of Pre-service Teachers' Error Analysis Skills in Teaching Differential Calculus
}

\author{
Chipo Makamure \\ Department of Mathematics Education, University of South Africa, South Africa
}

Received August 5, 2021; Revised September 30, 2021; Accepted October 21, 2021

\section{Cite This Paper in the following Citation Styles}

(a): [1] Chipo Makamure, "Examination of Pre-service Teachers' Error Analysis Skills in Teaching Differential Calculus," Universal Journal of Educational Research, Vol. 9, No. 11, pp. 1826 - 1840, 2021. DOI: 10.13189/ujer.2021.091103.

(b): Chipo Makamure (2021). Examination of Pre-service Teachers' Error Analysis Skills in Teaching Differential Calculus. Universal Journal of Educational Research, 9(11), 1826 - 1840. DOI: 10.13189/ujer.2021.091103.

Copyright $\mathrm{C} 2021$ by authors, all rights reserved. Authors agree that this article remains permanently open access under the terms of the Creative Commons Attribution License 4.0 International License

\begin{abstract}
Error analysis has been considered indispensable in teaching mathematics in classrooms worldwide. One of the greatest skills in mathematics teaching has been recognised as the ability to model learners' misconceptions through error analysis. The use of error analysis in the classroom has therefore made tremendous contribution to mathematics teacher knowledge. However, despite the acclaims about error analysis in teaching mathematics, researchers and teachers lack a detailed understanding of mathematics teacher knowledge as it is used in error analysis and the use of error analysis is still regarded as challenging for most teachers. This qualitative study therefore explored eight purposively selected pre-service teachers' ability to identify, interpret and remediate learners' error patterns as a result of misconceptions in differential calculus. The pre-service teachers' analyses were re-analysed by the researcher to ascertain their ability to handle learners' errors in mathematical calculus. The study established that though some pre-service teachers portrayed knowledge of the differentiation content as reflected by their ability to identify the errors made, most of them failed to identify the possible causes of the errors as well as provide appropriate instructional strategies that could be used to remediate learners' error patterns. This finding illustrates that the pre-service teacher's ability to diagnose, interpret and correct errors in learners' work, with targeted instruction is an essential and necessary skill for good mathematics teaching.
\end{abstract}

Keywords Differential Calculus, Error Analysis, Errors, Misconceptions, Pre-service Teachers

\section{Introduction}

Error analysis has been recognised by teachers and scholars as an inseparable part of the routine of teaching mathematics [1]. It has also been preferred by most researchers as an instructional strategy that assists mathematics learners to retain their learning [2]. One of the greatest expertise of teachers is therefore considered as their capability to synthesise an explicit model of a learner's misconceptions from the meagre evidence endowed in the learner's errors, [1] p. 155-156). The common statement, "we learn from errors..." justifies the need to analyse errors in learners' work. Russell et al. [3] agree with this statement and affirm that the most powerful learning experiences often result from making errors, which are highlighted, analysed and remediated by the teacher. This is because if an individual discovers her errors, it is rare to repeat that error, which becomes a break-through in learning mathematics. The immediate remedy to the errors made by learners is therefore essential and this dictates the need to analyse errors as part of teaching mathematics.

McGuire [4] foregrounds that teachers must not only possess strong mathematical content knowledge, but also the ability to focus on learners' levels of understanding a concept. The teacher's ability to diagnose and remediate common errors in learners' work with targeted instruction is thus a crucial and necessary skill for good mathematics teaching. 


\subsection{Problem Statement}

Although error analysis has been considered as a significant task in teaching mathematics, Pomalato et al. [5] aver that it is more challenging for mathematics teachers, especially in calculus. Despite a wealth of results about mathematics teaching knowledge, there is a lack of detailed understanding regarding mathematics teaching knowledge as used in error analysis [1]. Legutko [6] established that nearly all mathematics teachers encounter learners who make errors on a daily basis, but the problem is that mathematics curricula in teachers' training institutions do not encompass "error analysis" as a major topic, yet it is this topic that has become the backbone of all success in teaching and learning mathematics. [1] concur that mathematics programmes and curricula for teachers can therefore become less effective if they are not contextualised within the framework of teacher knowledge that informs error analysis. This paper explores the pre-service teachers' ability to identify, describe and interpret learners' common error patterns as a result of misconceptions in differential calculus. The following research questions inform this study:

(i) What common errors are made by ' $\mathrm{A}$ ' level learners in differential calculus?

(ii) How do pre-service teachers diagnose, interpret and remediate the errors made by learners in differential calculus?

\subsection{Literature Review}

\subsubsection{The Anatomy of Errors and Mistakes?}

According to [7], during error analysis, pre-service teachers might fail to distinguish "slips" from "bugs". 'Slips' are generally not due to inherent misunderstandings. Slips may be due to memory deficits, and are easier to identify than conceptual errors [7]. Conceptual errors or 'bugs' on the other hand occur because the student does not fully understand a specific mathematics concept [8]. According to [8], normally teachers focus more on mistakes than errors during error analysis. The two terms, namely error (bugs) and mistake (slips) are often used interchangeably. According to [6], these terms are however different. Legutko [6] describes a mistake as one that is made when an individual, for example, incorrectly applies a formula or a theorem that he/she knows. However, an error reveals the inadequacy of knowledge and is closely connected with limitations of imagination and creativity in new situations [6]. The definition suggests that an error is caused by an insufficient mastery of basic facts, concepts and skills. It is believed that an error takes place when a person chooses something false as the truth. Some misunderstanding of these terms may therefore impel pre-service teachers to neglect conceptual understanding of learning mathematics in favour of procedural/factual corrections during error analysis [7]. These concerns, hence, need to be addressed in teacher training programmes because knowledge of their difference is likely to determine how a teacher approaches learners' specific/individual problems.

\subsubsection{What is Error Analysis?}

$[4,8]$ define error analysis as the ability to identify and interpret learners' errors in learners' work with a view to finding possible explanations about these errors. Shulman [9] confirms that the ability to identify learners' errors enables teachers to become more acutely aware of the process of learning and the aspects of mathematics that are difficult to grasp. In addition, error analysis is essential, especially in the process of introducing new concepts, as it informs the teacher what to clarify, what to focus on and how to negotiate the comprehension of new concepts in order to avert errors [2]. These views imply that error analysis is capable of empowering teachers to assist learners to grow out of their misconceptions. In this way, the PSTs' teacher knowledge of mathematical cognition and concept development are thus broadened [8]. This knowledge of awareness of learners' errors hence draws a line that marks the difference between experienced and novice teachers [8]. Generally, the definitions alluded to above imply that error analysis assists teachers to understand learners' thinking which can actually enable teachers to adjust their teaching practices that include the way teachers assess learners' work, hence improving learners' performance in mathematics.

\subsubsection{Types of Errors in Relation to Error Analysis}

According to [10], learners make various errors when performing mathematical tasks. Errors in mathematics include misinterpreting mathematical expressions and misapplying mathematical properties [10]. Teachers need to be aware of these errors for effective error analysis. According to [11], the first step of error analysis should include the identification of the error displayed in the learners' work. The second stage involves finding out why the learner made that error, for example, it can be due to a lack of knowledge or understanding [12]. Lai [11] identifies 3 types of errors. First, there are procedural errors where a learner fails to follow the correct steps to solve a problem. The second type is the factual error. These are mistakes that some learners make when they cannot recall a fact required to solve a problem. According to [11], procedural and factual errors are also called 'slips'. These are normally not caused by inherent misunderstandings and are easier to identify. The third error, according to [11], is a conceptual error (bugs). These types of errors may look like procedural but are caused by the fact that the learner does not understand a specific mathematics content [8]. That means 'bugs' are more serious errors. A conceptual error is normally made if a learner cannot show and explain the steps used to solve the problem [12].

$[13,14]$ assert that all errors must be defined by the 
three activities, namely syntactic elaboration, semantic elaboration and strong parallel activities. According to these researchers, syntactic thinking involves the learner incorrectly manipulating the problem but generally understanding the concept. In semantic elaboration, the learners can work through all the steps of a mathematical problem but do not understand the problem. Strong parallels are between syntactic and manipulation errors and semantic thinking and conceptual errors.

However, despite different types of errors that exist, literature, for example, [2,5], focuses on two types of error analysis. The first type includes identification and interpretation of learners' common error patterns as a result of misconceptions. In this type of analysis, teachers need to possess strong mathematics content in addition to the ability to focus on learners' level of understanding. The ability to interpret learners' level of understanding has been regarded as a skill for good teaching [4]. The second component of error analysis involves teachers' best practices for instructional remediation. This implies that the teacher should come up with the best strategies of teaching mathematics to address particular individual learners' ascertained errors.

\subsection{Theoretical Considerations}

Despite the general consensus that error analysis is an essential task needed for mathematics teaching, a study by Morris, et al. [15] revealed that pre-service mathematics teachers lacked the ability to effectively plan and evaluate learners' mathematical thinking. Herholdt and Sapire [8] hence advise that errors must not be superficially described but must be embedded in the knowledge of why, when and how learners learn mathematics. In their study, [8] also contend that, during error analysis, teachers should focus on: (i) Correct methodologies of the test takers. According to [8], focusing on methodologies gives an insight into what is working rather than jumping into what is not. (ii) Find out whether a "correct" methodology used leads to a final answer that is "incorrect" (defective algorithm error by [16]. (iii) Focus on questions not attempted which could be an indication the of area of weakness, hence full attention would be required. (iv) Identify the most commonly occurring errors per item. A prevalence of such errors could be a sign of general confusion which could reflect the need for further clarification of the concept.

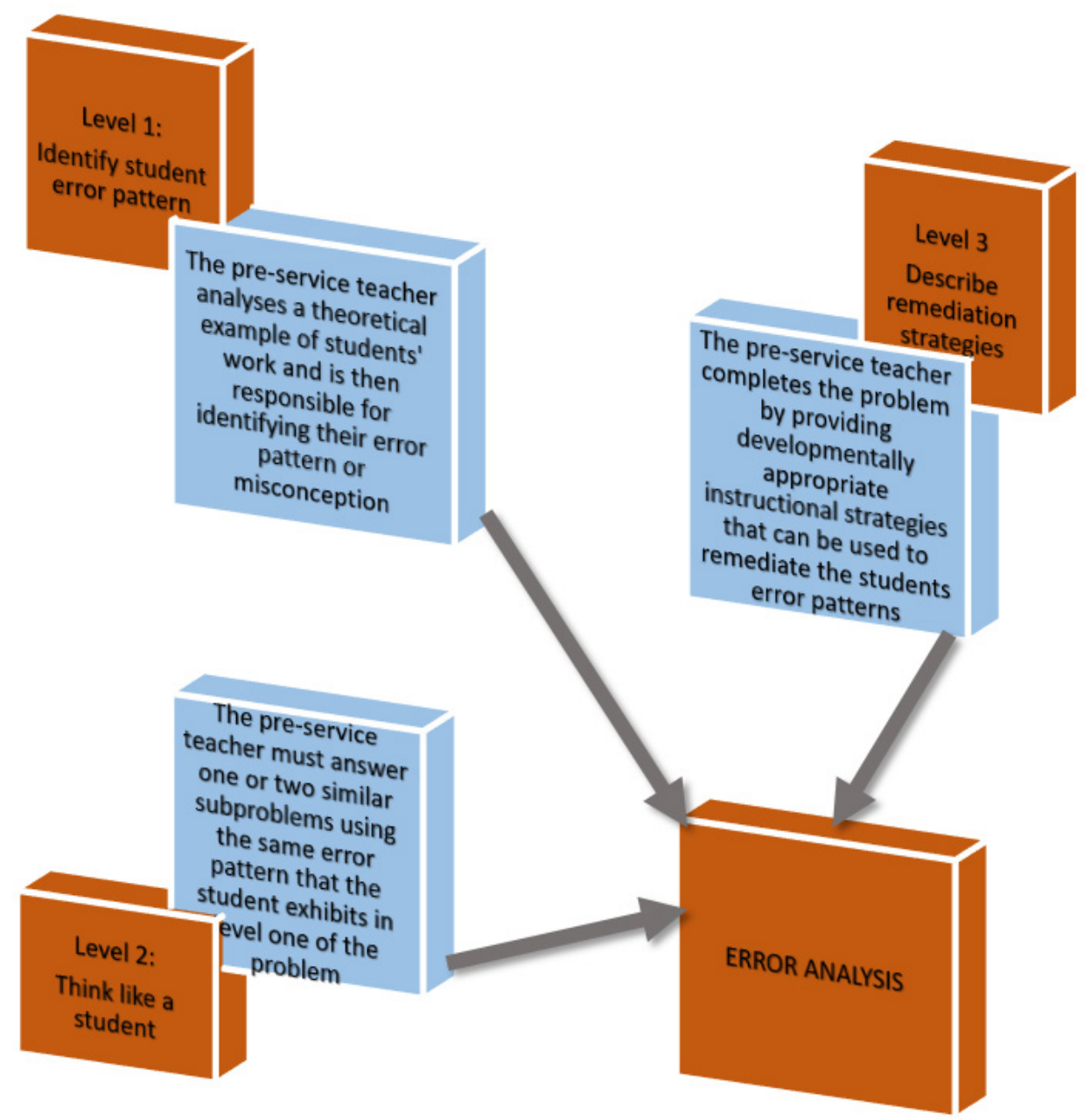

Figure 1: Adjusted 3-level problem structure of error analysis by Beatty and Gerace (2009) [17] 
Beatty and Gerace [17] also developed a theoretical framework on error analysis that included three related levels as a way of facilitating the process of error analysis among teachers. The adjusted overview of the error analysis 3-level problem structure is shown in Figure 1.

Despite teachers encountering learners who make mathematical errors on a daily basis, many pre-service teacher courses do not include authentic opportunities for pre-service teachers to analyse and discuss common errors [17]. This paper describes how preservice mathematics teachers analyse and remediate learners' work.

Rohmah and Sutiarso [18] presented the Newman's theory mistake analysis stages. It is pertinent for PSTs to be privy to Newman's model in order to determine learners' misconceptions in solving mathematics questions [19]. Newman's error analysis (NEA) can assist PSTs to diagnose students' errors in solving higher-order thinking skills in mathematics [20,21]. According to [18], there are five stages in recognising students' errors in the Newton error analysis (NEA) model and these are: i) Reading and decoding, which refer to the ability to read mathematical problems and identification of mathematical symbols used. ii) Comprehension, which refers to the students' understanding in relation to the symbols and problems given in the questions. iii) Transformation, which refers to the ability of learners in choosing the appropriate formulae or method to solve the problems given. iv) Process skills where learners use rules to solve a problem but make some computation errors in the process. Finally, v) Encoding, which is the ability of the students to generate and justify the answer they give.

\subsection{Theoretical Framework}

This study was underpinned by [1]'s framework for examining mathematics teacher knowledge as used in error analysis. This framework was developed from the theoretical considerations of [9]'s study on teacher knowledge. Shulman [9] developed the theory of teacher knowledge in relation to PCK. [9] suggested that a teacher's knowledge of the level of understanding of learners contributes to the teaching and learning of mathematics and awareness of the concepts that learners grapple with in the subject. [9] also emphasised the concept of subject matter knowledge (SMK) and pedagogical content knowledge (PCK). According to [9],
SMK involves knowledge of facts and concepts and understanding of the subject structure. This is equivalent to common content knowledge, that which any reasonably educated person should know and be able to do [22]. This knowledge includes the ability to identify incorrect answers or inaccurate definitions, and the ability to successfully complete the students' problems. It also includes specialised content knowledge, which teachers know and do but not necessarily other adults [23]. On the other hand, PCK is what makes the learning of specific topics easy or difficult because it is the amalgam of knowledge of content and teaching, knowledge of content and learners and knowledge of the curriculum. PCK, according to [9] is also regarded as a framework through which researchers can assess teacher knowledge and skills in respect to error analysis. It provides an analytical lens that can be used to observe the instructional decisions that teachers make [10].

Sousa [24] and [16] focus on error analysis as a teaching strategy that facilitates grasping learners' level of conception in mathematics. Given the theoretical considerations of [9], [24] and [16], it is evident that error analysis is intertwined with teachers' content and PCK, as well as teachers' knowledge of mathematical cognition [8]. The knowledge of content and students hence involves the ability to anticipate learners' errors, interpret learners' thinking and predict how learners would handle certain tasks [23].

Considering the complexity and significance of error analysis, literature, according to [1], does not provide a coherent picture of mathematics teacher knowledge in error analysis. The categories of teacher knowledge investigated to date are not closely related to error analysis. However, [1] developed a more comprehensive framework describing mathematics teacher knowledge in error analysis. According to [1], 4 keys of the nature of mathematical error from learners' perspectives were identified as mathematical, logical, strategic and psychological. From the teachers' perspectives, [1] also identified the 4 keys phrases of error analysis, namely identify, interpret, evaluate, and remediate. Comparing the nature of mathematical error and the phrases of error [1] with the category of SMK and PCK [9], the framework proposed by [1] for examining mathematics teacher knowledge as used in error analysis is detailed in Table 1 below: 
Table 1. Framework for examining mathematics teacher knowledge as used in error analysis (Peng \& Luo, 2009) [1]

\begin{tabular}{|l|l|l|}
\hline Dimension & Analytical categorization & Description \\
\hline \multirow{5}{*}{ Nature of mathematical error } & Mathematical & $\begin{array}{l}\text { Confusion of concept and characteristics, negligence of the condition of } \\
\text { formulas and theorem }\end{array}$ \\
\cline { 2 - 3 } & Logical & $\begin{array}{l}\text { The false argument, rearrange concept, improper classification, argue in } \\
\text { a circle, equivalent transform }\end{array}$ \\
\cline { 2 - 3 } & Strategic & $\begin{array}{l}\text { Couldn't distinct from the pattern, lack of integral concept, not good at } \\
\text { reverse thinking, couldn't transform the problem }\end{array}$ \\
\cline { 2 - 3 } & Psychological & Deficiency of mentality, improper mental state \\
\hline \multirow{5}{*}{ Phrase (Type) of error analysis } & Identify & Knowing the existence of mathematical error \\
\cline { 2 - 3 } & Interpret & Interpreting the underlying rationality of mathematical error \\
\cline { 2 - 3 } & Evaluate & $\begin{array}{l}\text { Evaluating students' levels of performance according to mathematical } \\
\text { error }\end{array}$ \\
\cline { 2 - 3 } & Remediate & Presenting teaching strategy to eliminate mathematical error \\
\hline
\end{tabular}

\section{Materials and Methods}

\subsection{Sampling}

This qualitative study involved eight Bachelor of Education (BEd) mathematics students from a certain university in Zimbabwe who were purposively selected to participate in the study. These were secondary school mathematics specialist trainees and the university admission requirements demanded a holder of a diploma in education (secondary) with mathematics as a major. The participants in their second year of the program, had covered all their pedagogical courses, and teaching practice was a compulsory component in their program. Pre-service teachers who had done their teaching practice were therefore considered in this study because the instrument used in the research was based on the pre-service teachers' experiences of teaching. After successfully completing this programme (BEd), the graduates would be expected to teach high school mathematics up to an advanced level ('A' Level).

\subsection{Procedure and Design}

The eight BEd mathematics pre-service teachers who were selected to participate in the study were asked to analyse learners' work on differential calculus in order to explore, identify and remediate the errors made. The data collection procedure involved 'differentiation' question items that were distributed to 3 ' $\mathrm{A}$ ' level learners to answer. Out of the five questions given, only one in which common errors were reflected was selected for analysis. The other five questions (to make them a total of six questions) comprised intentionally designed errors by the researcher. The answer scripts of the learners and the intentionally designed answers were then given to eight purposely selected pre-service teachers to mark the work, describing and detailing the errors made by the learners where necessary. A mark or score was allocated for each stage of the solution to the 6 questions. Each of the eight pre-service teachers marked the six answer scripts. All the eight participants did their learners' error analysis electronically. The use of the electronic means to participate in the study was in line with the social distancing requirements of the Covid-19 pandemic.

\subsection{Analysis}

On analysing the results, learners' errors were analysed first by the researcher. The pre-service teachers' analyses of learners' errors were then also re-analysed by the researcher. The data collected were analysed using Newman's theory of error analysis based on four indicators, namely comprehension error or error understanding problem, transformation error, process skill error, and encoding error or error writing an answer in order to determine what the learners were doing [5]. After that, mathematics teacher knowledge as used in error analysis was matched with the proposed framework by [1]. The researcher analysed the participants' analysis of learners' errors in response to the questions: What kind of errors were made? What are the possible causes of the errors (misconceptions that propagated the errors) and how can the errors be remediated? (instructional strategies that can be used to remediate the learners' error patterns). Responses to these questions were used as indicators to identify the pre-service teachers' error analysis skills. In addition, the analyses done by the pre-service teachers on the learners' scripts were compared to ascertain the various skills of error analysis among the pre-service teachers.

\section{Results and Findings}

The reflections of the PSTs who were involved in the analysis of learners' work were not written separately because most of the reflections were similar. Each question item for the learners was discussed using some representative excerpts from the participants. In each case, the researcher started by describing the errors made by the learners and then re-analysed the pre-service teachers' analyses of the same errors. After asking the pre-service 
teacher participants to scrutinise learners' work on differential calculus, the following results were presented:

\section{Question 1}

A man wishes to fence in a rectangular enclosure of area $128 \mathrm{~m}^{2}$. One side of the enclosure is formed by part of a brick wall already in position. What is the least possible length of fencing required for the other 3 sides? Show all your work.

The answers to this question by learners $\mathrm{A}, \mathrm{B}$, and $\mathrm{C}$, respectively, are presented in the appendices.

From the three responses to question 1, it is clear that there were conspicuous errors made by the learners. Learner B's work reflected some comprehension errors in accordance with the theory of error analysis [18]. The learner failed to capture all the information contained in the question in order to solve the problem. For example, given an enclosure with 3 sides to be fenced, the learner, although showing an idea that the expression for perimeter (P) should be differentiated and equated to zero for the minimum value of $\mathrm{P}$, was using the wrong value of $\mathrm{P}$. The learner minimised the perimeter of the entire rectangle (all 4 sides) instead of the perimeter for the three sides that needed fencing. The learner wrote: $\mathrm{P}=2(\mathrm{~L}+\mathrm{W})$. However, this should have been $\mathrm{P}=2 \mathrm{w}+l$. After calculating $\mathrm{w}=\frac{128}{l} \rightarrow \mathrm{P}=2\left(\frac{128}{l}\right)+l . \Rightarrow \mathrm{P}=\frac{256}{l}+l . \Rightarrow$ $\mathrm{P}=l+256 l^{-1}$

$$
\begin{aligned}
\therefore \frac{d p}{d l}=1-256 l^{-2} & =0 . \Rightarrow 1-\frac{256}{l^{2}}=0 . \Rightarrow l^{2}=256 . \quad \Rightarrow l \\
& =16, \text { Hence, } w=8 .
\end{aligned}
$$

Therefore, the minimum length $(\mathrm{P})=2(8)+16=$ 32 metres.
The bulky of the pre-service teachers identified this error when they analysed learner B's errors. However, some of them failed to realise the error. For example, PSTs Steve and Wadzie seemed to be experiencing the same misconceptions as the learner. They were satisfied with learner B's answer and scored $100 \%$ on the given solution where 4 sides were considered to find the perimeter of the 3 sides. This could be a sign of content knowledge deficiency on the part of the PSTs, which is likely to have an impact on the learners' conceptualisation of and performance on differentiation concepts.

Learner A erred by choosing $x+2 x$ to represent the length of the rectangular model. This seemed to be a random representation of the length without basis, hence it was cumbersome to establish the learner's thinking pattern on this question. Although most PSTs identified this error, their explanation about the causes of the error and remediation strategies left a lot to be desired. The PSTs explained that the learner had challenges in differentiation. However, the researcher would want to argue that the major challenge was that the learner failed to master the basic concepts or pre-requisites of algebra prior to the introduction of differential calculus. This is because the learner could not even label the model properly in addition to failing to understand the concept of perimeter required by the question. It is essential to identify the root cause of an error in mathematics because this can prevent similar errors to re-occur. Learner ' $A$ ' proceeded to finding the area of the model which was out of the question. A total of $5 / 8$ PSTs did not mention in their analysis that learner ' $A$ ' was supposed to find the perimeter of the model as required by the question. For example, Steve's analysis is shown below. The PST's comments are shown in red.

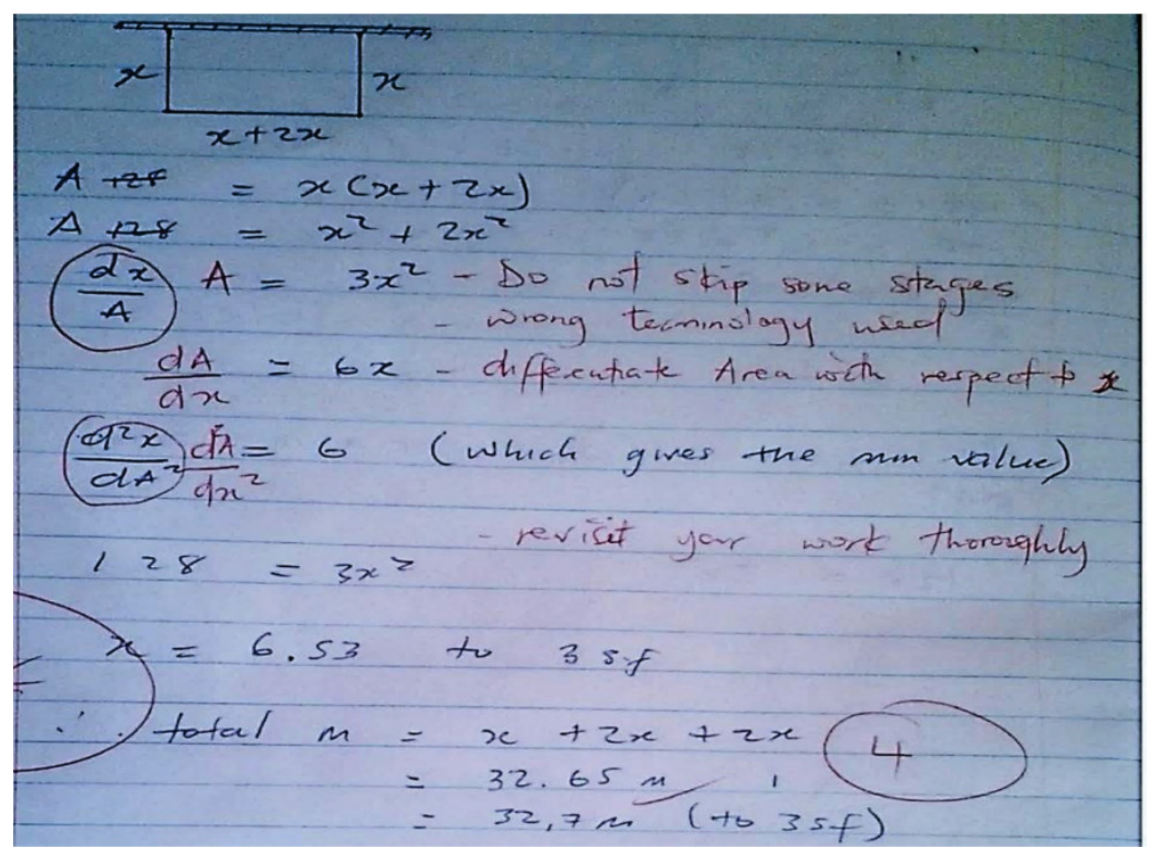

Figure 2. Steve's Analysis of Question 1 
Steve focused on analysing factual errors such as 'wrong terminology used, skipping some stages, revisit your work thoroughly' thereby ignoring the conceptual and/or procedural errors made, that is, failure to find the perimeter required by the question and failure to differentiate the perimeter to find the minimum perimeter, respectively. To also confirm the PST's lack of knowledge on the question, Steve proceeded to score 4/5 $(80 \%)$ for the solution provided by learner A.

Another pre-service teacher, Dester, commented on learner A's solution as follows:

"Concept of the perimeter is correct but an expression for length is not justified"

This was a worrisome analysis because the learner did not even attempt to find the perimeter, instead, the learner calculated the area.

The same learner ' $A$ ' on differentiating the area (which was a wrong procedure anyway), wrote; $\frac{d x}{d A}=3 \mathrm{x}^{2}$. First, the derivative of $x^{2}+2 x^{2} \neq 3 x^{2}$. Second, the learner, by writing $\frac{d x}{d A}$, seems to be trying to find the rate of change of area (A) w.r.t $x$ (i.e, $\frac{d A}{d x}$ ) but, instead, wrote $\frac{d x}{d A}$. Learner ' $A$ ' seemed not to understand the difference between the two terms and this could be evidence of the deficiency of content knowledge of derivatives on the part of the learner. The error recurred on $\frac{d^{2} x}{d A^{2}}$ and this could denote the error of comprehension. The errors mentioned above hindered the learner from processing further the solution from the problem.

On analysing the PSTs' analysis of this learner's error, only $3 / 8$ PSTs identified this error and the rest were silent about it. This could be ascribed to several reasons, for example, some could have ignored the error because it had nothing to do with the expected solution, that is, the error was concerned with area, when the solution expected perimeter. However, that misconception of differentiating an expression wrongly and writing the differential term incorrectly should have induced some goose bumps on the PSTs. The other reason why the PSTs could have chosen to leave it out could be that they did not notice the error because they did not know either. However, for the three that identified the error, not even one of them provided remediation to this error in order to install understanding of the concept in the learner.

Learner C did not have the sense of the question at all. The PSTs' analysis was very clear as to describing the dilemma faced by learner C. However, some of them dared not to explain how such a learner could be assisted. Here is what PST Steve reiterated:

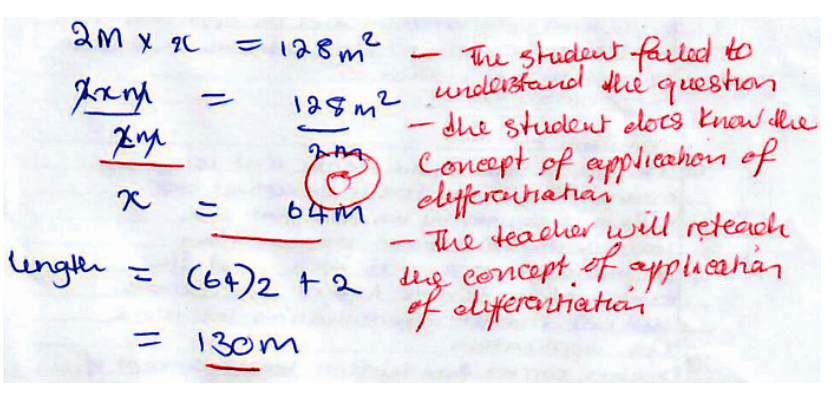

Figure 3. Steve's Analysis of Question 1C

Unlike Kaine who advised to revisit concepts on algebra first and then model the problem before differentiation is introduced, Steve focused on the fact that the answer was wrong (factual error) and talked about just re-teaching as a way of assisting the learner. The main concern with re-teaching as a strategy of remediation is that Steve did not specify the stage from which he had to re-teach, whether it was algebra or basic differentiation, which concepts and how to teach them. On the contrary, Tind had this to give:

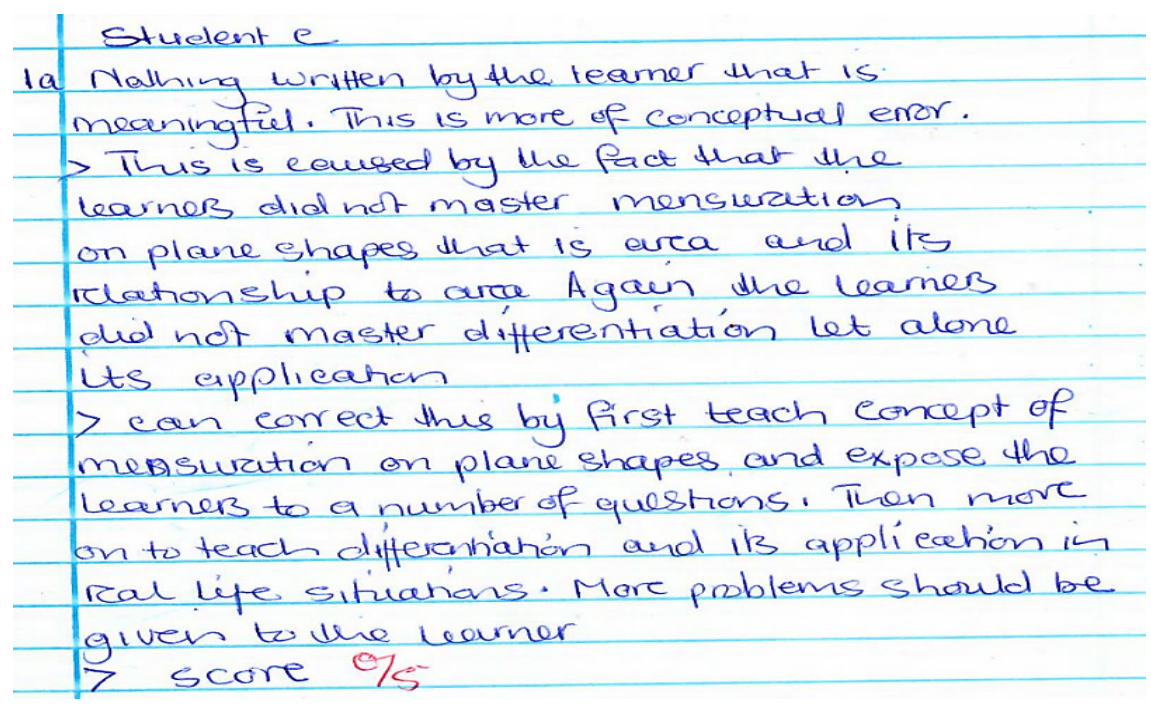

Figure 4. Tind's Analysis for Question 1C 
Tind realised that the learner had challenges with pre-requisite concepts like mensuration of plane shapes that needed to be understood first before the introduction of differentiation. However, his explanation excluded perimeter which was required by the question.

\section{Question 2}

Find $\frac{d y}{d x}$ where $\mathrm{x}$ and $\mathrm{y}$ are related by the equation: $\mathrm{x}^{2} \mathrm{y}$ $+2 x y^{2}=0[5]$

Given below is the solution to the question above, provided by one learner:

$$
\begin{gathered}
\left(2 x y+x^{2} \frac{d y}{d x}\right)+\left(2 y^{2}+2 x y \frac{d y}{d x}\right)=0 \\
\left(x^{2}+2 x y\right) \frac{d y}{d x}=-2 x y-2 y^{2} \\
\frac{d y}{d x}=\frac{-2 \mathrm{xy}-2 \mathrm{y} 2}{x^{2}+2 x y}
\end{gathered}
$$

In question 2, the learner demonstrated quite good knowledge of algebra. The answer also portrays the learner's ability to apply the product rule in differentiation. However, in the process, the learner made some computation errors which seemed to be a mere mistake rather than a misconception. According to [18]'s theory of error analysis, this error can be categorised under process skill error. This is when a learner makes use of rules to solve the problem correctly but in the process, makes mistakes in computations.

All the eight PSTs managed to identify and interpret the error made, but none of them solemnly provided strategies to solve the problem, neither did they suggest possible causes of the error. It is important to be privy to the causes of errors made in mathematics so that if the cause is fixed, similar errors will not occur. Strategies to handle and correct the error are also crucial as this may aid teacher knowledge for teaching mathematics in PSTs.

\section{Question 3(a)}

The solution provided below was adapted from [25]:

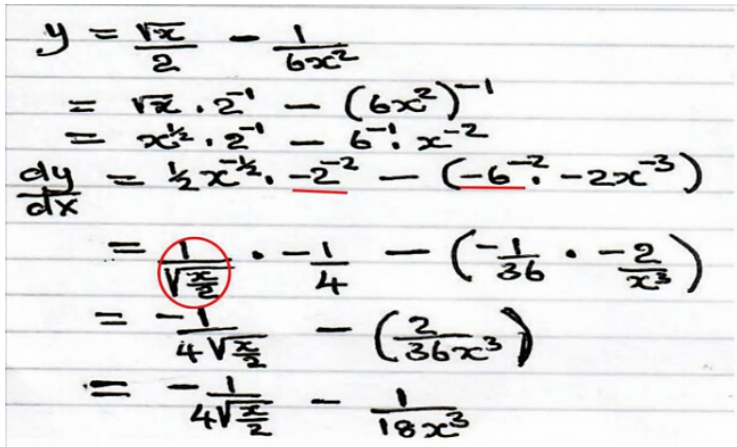

Figure 5. Adapted from Makonye (2016) [25]

In the solution, the learner shows high degree of indices competency as reflected by the procedures followed from lines 1 to 3 . However, the learner found the derivative of both the constant and the variable and treated both of them as similar mathematical objects [25]. For example, in line $2,1^{\text {st }}$ part, $\frac{d}{d x}\left(\frac{\sqrt{x}}{2}\right) \ldots$. is expanded as:

$$
\begin{gathered}
\frac{d}{d x}\left(\sqrt{x} \cdot 2^{-1}\right)=\frac{d}{d x}\left(\mathrm{x}^{1 / 2} \cdot \underline{\left.2^{-1}\right)}\right. \\
=1 / 2 x^{\frac{-1}{2}} \cdot-2^{-2} \ldots \cdots \cdots
\end{gathered}
$$

The learner was oblivious of the fact that differentiation using the power rule applies to variables only (comprehension error). The error of differentiating a constant was also systematic as it was made several times in the same question. These errors culminated into more errors in the process of solving the problem. The learner also made an error when he wrote;

$$
1 / 2 x^{-1 / 2}=\frac{1}{\sqrt{x / 2}} \text {, which is an executive error [25] }
$$


On analysing pre-service teachers' analysis on this solution, all the pre-service teachers indicated where the error was in the solution. They explained the anomaly of differentiating constants as variables. In most cases, PSTs' various ways of remedying the errors made were unique. Some indicated the error of differentiating constants without suggesting what the learner could have done or averted. They ought to provide some proof to convince the learners that what they did was indeed incorrect. They did not suggest the possible causes of the errors; neither did they suggest some possible remedies to the errors. They also did not explain why the constants in the function could not be differentiated so that the learner could understand the error instead of just memorising the fact that constants cannot be differentiated. However, responding to the errors made by the same learner, some pre-service teachers like Tind had this to say:

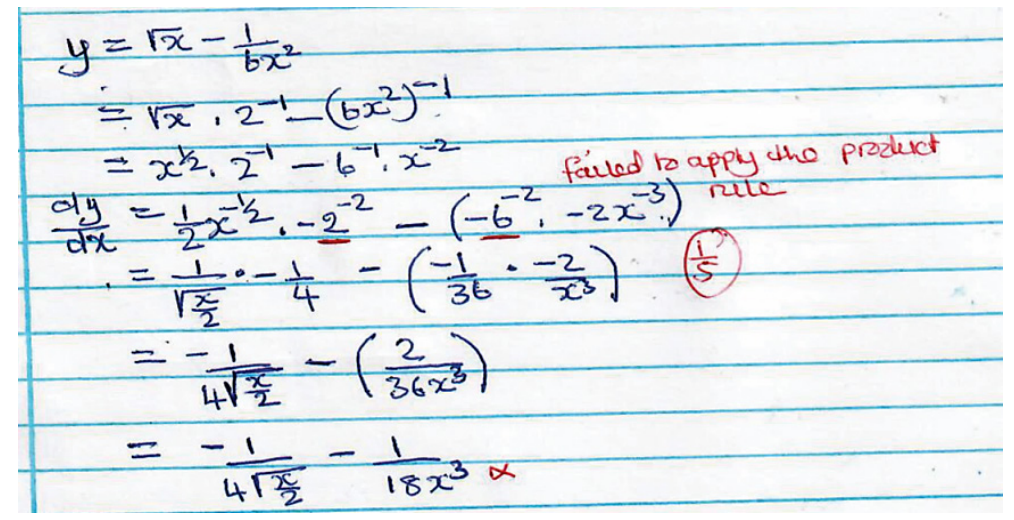

Figure 6. Tind's Analysis of Question 3(a)

Pre-service teacher Tind recommended the learner to use the product rule without explaining how the product rule would apply on such a question, or where the rule seems to be irrelevant. This reflects the idea that Tind did not know why constants cannot be differentiated and when and how the product rule works.

Petty also suggested the following:

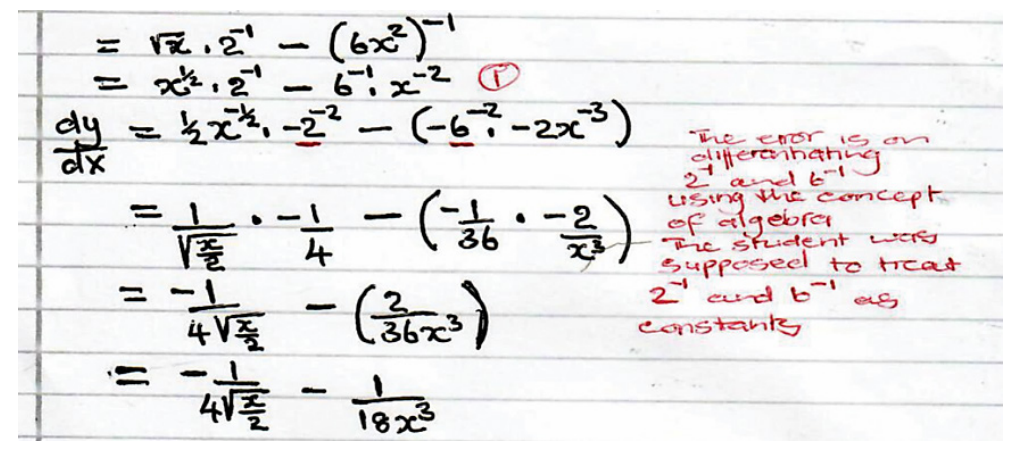

Figure 7. Petty's Analysis of Question 3a

Petty recommends that the learner should treat $2^{-1}$ and $6^{-1}$ as constants. However, the worrisome questions that the learner could have in mind are that: "How are the constants treated? Why can they not be differentiated?" The PST should have explained to support the recommendation/ assertion.

Steve had this to say about the learner's solution:

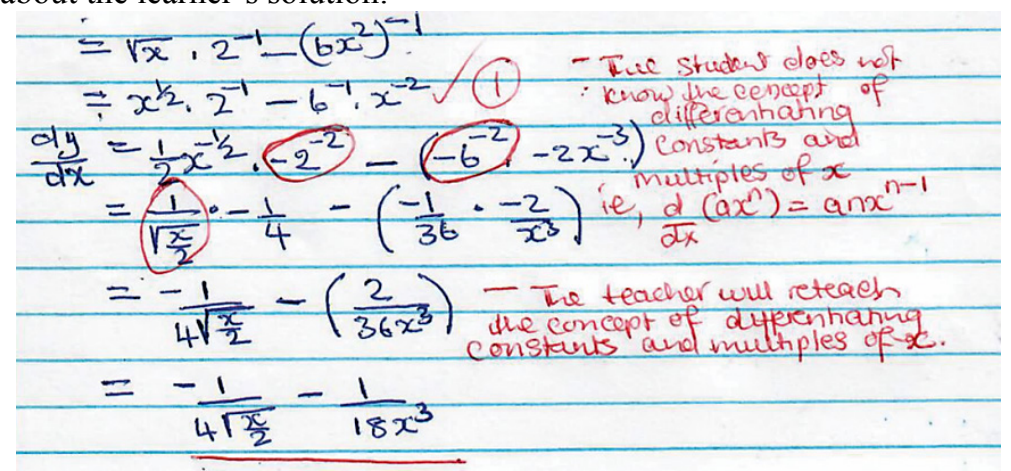

Figure 8. Steve's Analysis for Question 3a 
The idea of re-teaching suggested by Steve as a way of remedying the error seems not to work in such circumstances. The error should be corrected by explaining or clarifying misconceptions. By re-teaching the PST may repeat the same mistakes that lead to the same error. Steve also suggested the use of the rule $\frac{d}{d x}\left(\mathbf{a} x^{\mathrm{n}}\right)$ $=\mathbf{a n} \boldsymbol{x}^{\mathbf{n}-1}$. However, for a learner who has some misconceptions of this type, this may encourage memorisation without understanding, hence the problem can propagate into worse challenges where learners may fail to apply the rules in new contexts.

For all the participants, no satisfactory remediation was given, hence the researcher suggests that the use of 'differentiation from the first principles' would suffice to solve the problem of differentiating constants. For example, given that $\mathrm{f}(\mathrm{x})=\frac{\sqrt{x}}{2} \ldots$. Then

$$
\begin{array}{r}
\mathrm{f}^{\mathrm{l}}(\mathrm{x})=\lim _{\mathrm{h} \rightarrow 0} \frac{f(x+h)-f(x)}{h} \\
\mathrm{f}^{\mathrm{l}}(\mathrm{x})=\lim _{\mathrm{h} \rightarrow 0} \frac{\frac{\sqrt{x+h}}{2}-\frac{\sqrt{x}}{2}}{h}
\end{array}
$$

$\mathrm{f}^{\mathrm{l}}(\mathrm{x})=\lim _{\mathrm{h} \rightarrow 0}\left(\frac{\frac{\sqrt{x+h}}{2}-\frac{\sqrt{x}}{2}}{h}\right) \cdot\left(\frac{\frac{\sqrt{x+h}}{2}+\frac{\sqrt{x}}{2}}{\frac{\sqrt{x+h}}{2}+\frac{\sqrt{x}}{2}}\right)$ (Rationalising the denominator)

$$
\mathrm{f}^{\mathrm{l}}(\mathrm{x})=\lim _{\mathrm{h} \rightarrow 0} \frac{\left(\frac{\sqrt{x+h}}{2}\right)^{2}+\frac{\sqrt{x}}{2}\left(\frac{\sqrt{x+h}}{2}\right)-\frac{\sqrt{x}}{2}\left(\frac{\sqrt{x+h}}{2}\right)-\left(\frac{\sqrt{x}}{2}\right)^{2}}{h\left(\frac{\sqrt{x+h}}{2}+\frac{\sqrt{x}}{2}\right)} \text { Expand }
$$

$$
\begin{gathered}
\mathrm{f}^{1}(\mathrm{x})=\lim _{\mathrm{h} \rightarrow 0} \frac{\frac{x+h}{4}-\frac{x}{4}}{h\left(\frac{\sqrt{x+h}}{2}+\frac{\sqrt{x}}{2}\right)}=\lim _{\mathrm{h} \rightarrow 0} \frac{1}{h\left(\frac{\sqrt{x+h}}{2}+\frac{\sqrt{x}}{2}\right)}=\frac{1}{4 \sqrt{x}}= \\
\frac{1}{4} x^{\frac{-1}{2}}
\end{gathered}
$$

\section{Question 3(b)}

$$
\begin{aligned}
& \frac{d}{d x}\left[\left(x^{2}+5 x\right) \cdot \sin x\right]=\frac{d}{d x}\left(x^{2}+5 x\right) \cdot \frac{d}{d x}(\sin x) \\
& =(2 x+5) \cdot \operatorname{Cos} x=2 x \operatorname{Cos} x+5 \operatorname{Cos} x
\end{aligned}
$$

In her solution, the learner might be confused the rule $\frac{d}{d x}(\mathrm{f}(x)+\mathrm{g}(x))=\mathrm{f}^{\prime}(x)+\mathrm{g}^{\prime}(x)$ with the product rule $\frac{d}{d x}$ $[\mathrm{f}(x) \mathrm{g}(x)]=\mathrm{f}^{\prime}(x) \mathrm{g}(\mathrm{x})+\mathrm{f}(x) \mathrm{g}^{\prime}(x)$. The derivative of $\frac{d}{d x}[\mathrm{f}(\mathrm{x})$ $\mathrm{g}(\mathrm{x})] \neq \mathrm{f}^{\prime}(x) \mathrm{g}^{\prime}(x)$.

On re-analysing PSTs' analysis of the problem, this error was noticed by all participants. The narrative below is Kaine's analysis which is a representation of the position taken by all participants, (figure 9).

Kaine recommended the use of the product rule on the question, but however did not explain how the product rule could have been used. The error in the solution shows that the learner is not well acquainted with the product rule, but seems to know that $\left(x^{2}+5 x\right) \cdot \sin x$ means multiplication of two functions but still could not apply the product rule.

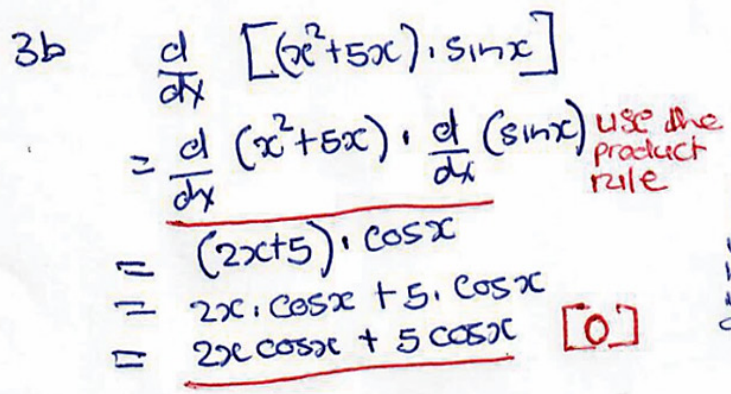

In this case stuelent B used a concept similar to the eddition Law of to the adiation which was inapplicable. student B noeds help to distinguish between where the esdalition Law $h$ as to be applied and where the product nile applies.

Figure 9. Kaine's Analysis of Question 3b 


\section{Question 3(c)}

The learner presented the work as follows:

$$
\begin{aligned}
\text { If } y & =\left(2 x^{2}-4\right)^{3} \text { then } \frac{d y}{d x}=3\left(2 x^{2}-4\right)^{2}=3\left(4 x^{4}-16 x^{2}\right. \\
+16) & =12 x^{4}-48 x^{2}+48
\end{aligned}
$$

In this solution, the chain rule was inappropriately applied. The learner could not apply the rule $\frac{d}{d x}[\mathrm{f}(\mathrm{g}(x))]=$ $\mathrm{f}^{\prime}(\mathrm{g}(x)) \cdot \mathrm{g}^{\prime}(x)$. Most participants realised that there was such an error of partially differentiating the function leaving out the derivative of $\mathrm{g}(x)$. However, the remediation process for most of them was quite controversial. PST 'Knowledge' presented the following analysis:

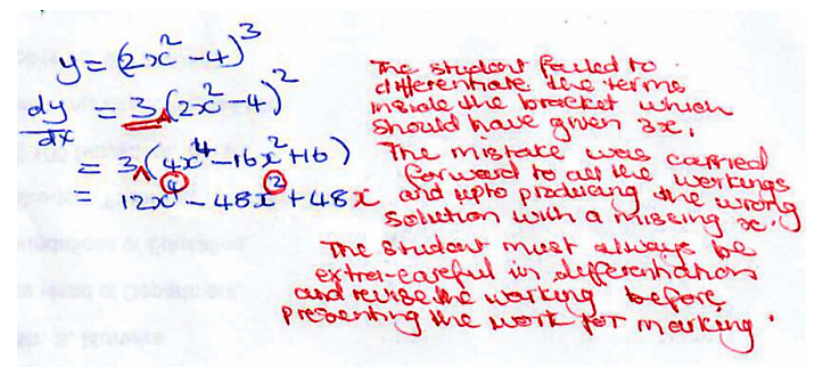

Figure 10. Knowledge's Analysis for Question 3C

Although Knowledge had an idea of how the function could be differentiated, the remediation suggesting $3 \mathrm{x}$ as the derivative of the function $2 x^{2}-4$ was wrong. In addition, advising the learner to be extra careful suggests that the error was a mere mistake made by the learner who understood the question, which might not be the case for this learner. Hence, extra care does not correct the misconception that the learner has in this case. Wadzie, another PST also had this to say:

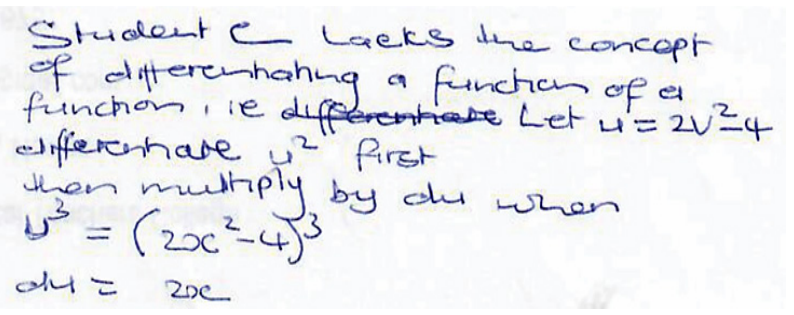

Figure 11. Wadzie's Analysis of Question 3C

The remediation given by Wadzie casts some doubt on whether the PST is knowledgeable about the content or not. In the given remediation, several errors are obtrusive.

From both Knowledge and Wadzie's analysis, the learners' challenges are likely to be exacerbated by the wrong feedback from the pre-service teachers. This is an indication of a lack of both content and teaching knowledge on the teacher which can have an academically devastating effect on the performance of the learner, as well as the pre-service teacher's skills to teach for understanding.

The picture of Dester's analysis on the same solution was illegible, hence it was clearly transcribed below. Dester's story goes as follows:

\section{C Comment}

To help the student, the teacher needs to give several aspects on how the different forms of algebraic terms have been differentiated. That is derivatives of terms that have no power and terms with powers, these have a different way of being differentiated. This is the kind of information the teacher has to teach the student so that they avoid making similar mistakes in future.

Dester's description is a reflection of a teacher who corrects learners' errors by drill and practice. The PST failed to pinpoint the root cause of the error and remove or fix it so that it is not repeated in future. With drill and practice, students may be relying on just remembering but do not really understanding the material properly.

Tind, another PST, also indicated that there was an error of omission in the solution. The researcher, however, contends that the learner's error could have something to do with comprehension of concepts and not necessarily omission because of failure to appropriately apply the chain rule concept.

As for PST Steve, the error was identified, correct answer suggested, but the remediation process was found wanting. Steve recommended re-teaching whilst emphasising the rule:

If $y=(a x+b)^{n}$ then $\frac{d y}{d x}=a n(a x+b)^{n-1}$. Introducing the rule without further explanation may be confusing for some learners. Depending on their level of aptitude, learners may fail to understand how 'an' outside the brackets of $\frac{\boldsymbol{d} \boldsymbol{y}}{\boldsymbol{d} x}$ was found. Learners may take it to say:

(i) the 'an' outside the bracket stands for the coefficient of the first variable $\boldsymbol{x}$ inside the brackets multiplied by the power ' $\boldsymbol{n}$ '. Once the concept is understood that way, a question like

$\mathbf{y}=\left(\mathbf{a} x^{2}+\mathbf{b}\right)^{n}$ could be differentiated as $\frac{d y}{d x}=$ (an $\left(a x^{2}+b\right)^{n-1}$ where ' $a$ ' is just the coefficient of the variable $\boldsymbol{x}^{2}$ multiplied by the power ' $\boldsymbol{n}$ '. This gives a wrong solution to the question asked.

(ii) $\mathbf{y}=(\mathbf{a x}+\mathbf{b})^{\mathbf{n}}$ then $\frac{d y}{d x}=\mathbf{a n}(\mathbf{a x}+\mathbf{b})^{\mathrm{n}-1}$ can also be misconceived as multiplying the power ' $\mathbf{n}$ ' by [the coefficient ' $\mathbf{a}$ ' of the first variable $\mathbf{x}$, multiplied by the power (in this case 1) of the variable $\mathbf{x}$ ] focusing on the first term in brackets only to get the answer. Understanding the concept that way may also give birth to the wrong answer on a question such as $\frac{d}{d x}\left(\mathbf{a x}^{2}+\mathbf{b}\right)^{\mathbf{n}}$, which can be wrongly written as $\frac{d}{d x}\left(\mathbf{a x}^{2}+\mathbf{b}\right)^{\mathbf{n}}=\underline{\mathbf{2 a n}}\left(\mathbf{a x}^{2}\right.$ $+\mathbf{b})^{\mathbf{n}-1}$.

To clarify the concept, Steve could have foregrounded the chain rule where

$$
\frac{d}{d x}[f(g(x))]=f^{\prime}(g(x)) \cdot g^{\prime}(x) \text { with } g^{\prime}(x) \text { representing the }
$$


derivative of the function inside the brackets of function $f$.

Using the same concept of the chain rule but explained differently, the process illustrated below can be used to avert or correct this kind of error:

$$
\begin{aligned}
& \text { If } y=\left(2 x^{2}-4\right)^{3}, \text { Let } \mathrm{u}=2 x^{2}-4, \Rightarrow y=u^{3} \\
& \frac{d u}{d x}=4 \mathrm{x} \text { and } \frac{d y}{d u}=3 \mathrm{u}^{2} \therefore \frac{d y}{d x}=\frac{d y}{d u} \cdot \frac{d u}{d x}=3 \mathrm{u}^{2} .4 \mathrm{x}= \\
& 3\left(2 \mathrm{x}^{2}-4\right)^{2} \cdot 4 \mathrm{x} \\
& \quad=12 x\left(2 x^{2}-4\right)^{2}
\end{aligned}
$$

In this way, the learner, instead of memorising the misunderstood procedures, may be able to conceptualise the chain rule.

\section{Question 3(d)}

Below is the solution to question 3(d):

$$
\frac{d}{d x}\left[\sin \left(7 x^{2}+4 x\right)\right]=\operatorname{Cos}\left(7 x^{2}+4 x\right)(14 x+4)=\operatorname{Cos}
$$

$\left(98 x^{3}+92 x^{2}+16 x\right)$

The concept in this question is similar to the one in $3 \mathrm{C}$. The only difference is that in $3 \mathrm{C}$, the learner inappropriately applied the chain rule whereas the learner here is aware of the chain rule $\frac{d}{d x}(\mathrm{f}(\mathrm{g}(x)))=\mathrm{f}^{\prime}(\mathrm{g}(x))$. $\mathrm{g}^{\prime}(x)$, hence the second stage $\operatorname{Cos}\left(7 \mathrm{x}^{2}+4 \mathrm{x}\right)(14 \mathrm{x}+4)$ is correct. However, the confusion was on whether the trig function 'Cosine' encompassed both $\left(7 \mathrm{x}^{2}+4 \mathrm{x}\right)$ and $(14 \mathrm{x}$ $+4)$. The learner made an error of expanding $\left(7 x^{2}+\right.$ $4 \mathrm{x})(14 \mathrm{x}+4)$ so that the product is under Cosine.

All the participants identified this error but the remediation was generally poor. However, using the concepts explained under 3C above would assist this learner as well.

\section{Question 3(e)}

Generally, the solution shows that the learners knew what was needed by the question except that in line 2, $d / d x$ is outside the brackets, implying that the learner is differentiating everything inside the brackets. However, the learner did not differentiate everything, but rather followed the correct procedures to get the correct answer. Not all pre-service teachers who analysed this solution identified this anomaly. PSTs, for example, Wadzie, and Kaine just assumed the answer was correct and scored 5/5 for this learner. However, one PST, Chips concluded that the error was so major that the learner did not deserve even a single mark. Here is what Chips did:

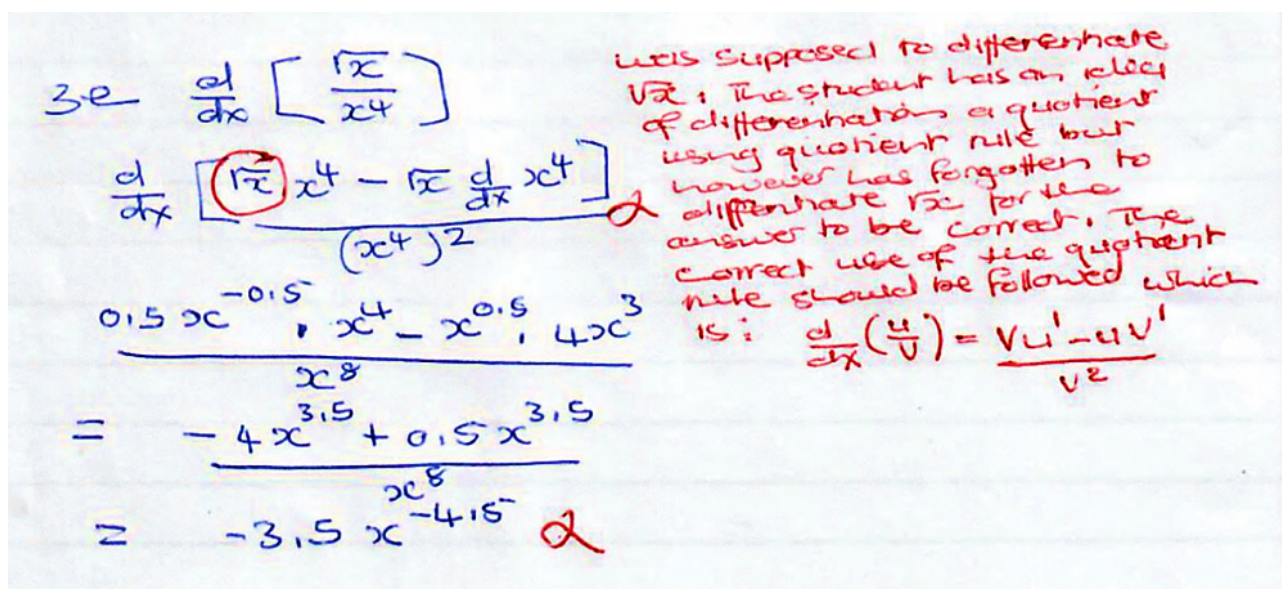

Figure 12. Chip's Analysis for Question 3e 
It is once more argued that the analysis of the error was done inappropriately because nearly all the steps were correct in the solution except for a 'slip' that occurred on misplacement of the bracket. In the remediation, Wadzie also suggested a shorter method of differentiating the function as follows:

$$
\mathrm{y}=\left[\frac{\sqrt{x}}{x^{4}}\right] \Rightarrow \mathrm{y}=x^{\frac{1}{2}} \cdot x^{-4}=x^{-3.5} \Rightarrow \frac{d y}{d x}=-3.5 x^{-4.5}
$$

This provides evidence of a good facilitation of the problem.

\section{Discussion}

The purpose of this study was to explore pre-service teachers' skills to analyse learners' errors as a result of misconceptions in differential calculus. The researcher analysed the learners' work first and then re-analysed the analysis of pre-service teachers on the same learners' work. The study identified some themes that included mathematics knowledge for teaching, challenges and opportunities experienced during error analysis. These challenges and opportunities include error identification, identification of error causes and remediation processes.

The findings of this study revealed that the PSTs struggled with the analysis of learners' errors. This was due to several reasons possibly emanating from a lack of content knowledge, a lack of teaching knowledge and a lack of knowledge of learners. As a result of these reasons, identification of errors, error types and remediation strategies were strenuous for most PSTs.

It is also argued that there is a possibility to identify the PSTs' mathematics knowledge level for teaching by comparing the learners' solutions and the PSTs' analysis of learners' errors in this study. The study established that the pre-service teachers' explanation about how errors can be remediated was not quite satisfactory. It can be argued that some PSTs gave seemingly impertinent explanations. In comparison with [1]'s theory, the PSTs could not recognise the nature of mathematical errors that were mathematical, logical and psychological, committed by learners. For example, PSTs like Wadzie and Steve confused concepts that involved the perimeter formula in question 1 (learner B). This was a reflection of PSTs' deficiency of teaching knowledge in the aspect of error analysis. As for the phrase (type) of error analysis [1], some PSTs could identify the student errors but could not explain the underlying rationality. There was no adequate interpretation and justification of the errors made despite identifying the errors. PSTs could identify the learners' errors but interpreted them with wrong mathematical knowledge; hence, the learners' performance was wrongly evaluated (see Figures $2 \& 6$ ). Failure to interpret the errors also resulted in PSTs coming up with unspecific/weak presentation of teaching strategies for certain types of concepts (Figure 10).
The study also found that it was less cumbersome for some pre-service teachers to identify where the errors existed in the solutions and thus was an indication of the existence of knowledge of content for the PSTs. However, knowledge of content is not adequate for a teacher if the PST cannot give satisfactory remediation for the learner to understand. McGuire [4] emphasised that error analysis does not just involve analysis of learners correct, partially correct and incorrect steps towards finding a solution, but also entails the best practices for remediation. This process, [4] maintains, that a teacher needs to be well acquainted with knowledge of learners' levels of mathematical understanding in addition to a good grasp of mathematical content.

According to [17]'s 3 level problem structure (Figure 1), after identifying learners' error patterns [17]'s level 1, PSTs should be able to describe remediation strategies for comprehension of the concepts taught. Beatty and Gerace [17] assert that pre-service teachers should complete the problem by providing developmentally appropriate instructional strategies that can be used to address the learners' error patterns. Instead, some PSTs in this study could not specifically address learners' particular weaknesses by providing remediation that suited the errors made.

According to [18]'s presentation of Newman's model of mistake analysis stages, there are different types of errors that include reading errors, comprehension errors, transformation error, process skill errors and encoding errors. It is essential to be privy to these various types of errors so that the teacher is able to remediate the learners' errors. However, most PSTs in the study, though they could locate the errors in learners' work, they could not distinguish the different types of errors. For example, where a conceptual error or a procedural error existed, some pre-service teachers would present it as an omission error (see Tind's analysis for question 3C). This means the error can then be addressed differently. This could impact on their teaching skills with respect to error analysis, and their ability to provide remediation can be compromised. By identifying learners' specific error types, the PST can provide instruction targeted to the learners' areas of need [11]

It was also found that some PSTs, though few, seemed to have challenges with their content which propelled poor, if not wrong descriptions of the remediation processes for the errors made. The study hence concurs with [9]'s theory of teacher knowledge, [24] and [16], that error analysis is intertwined with content, PCK, and knowledge of mathematical cognition. The knowledge of content and strategies thus involves the ability to identify learners' errors, to interpret learners' thinking and correct learners' work ([17]'s 3 level problem structure of error analysis). PSTs were also seen focusing on the basic facts rather than the pattern of errors which are procedural or conceptual (Figures $2 \& 3$ ). Attending to factual errors 
only at the expense of procedural/conceptual errors does not help to correct learners' misconceptions [11].

\section{Conclusions and Recommendations}

In conclusion, the analysis of literature and the data collected established that learners sometimes make conceptual errors in differential calculus because they lack basic knowledge of pre-requisite concepts such as algebra to solve problems on differentiation. However, it was also revealed that pre-service teachers share the same misconceptions as their learners. Arguably, the pre-service teachers' error analysis skills in differential calculus could be exacerbated by a lack of content knowledge on the topic. This was confirmed when some PSTs failed to identify the errors made by the learners because they themselves could not solve the problems. On the other hand, though some of the pre-service teachers were well acquainted with the content knowledge of differential calculus and could identify the errors made by learners, they could hardly provide appropriate instructional strategies that could be used to remediate the learners' error patterns [17]. This reflected a lapse in their mathematics teaching knowledge with respect to error analysis. It was also ascertained that some pre-service teachers could locate errors in learners' work but could not predict the source/cause of the error and the error type, that is, whether it was a conceptual error, an omission or a procedural error. By identifying learners' specific error types and sources, the PST can provide instruction targeted to the learners' areas of need [11]. This study established that some pre-service teachers (For example, see Figures $2 \& 3$ ) focused more on analysing factual errors than conceptual errors. Based on these findings, the study recommends that pre-service teachers be assisted with knowledge of error analysis to ensure their understanding of some learners' misconceptions of mathematical concepts and give these learners appropriate remediation. Teacher training programmes should therefore embrace and sharpen their focus on error analysis as a critical strategy of teaching mathematics for proficiency.

\section{REFERENCES}

[1] A. Peng, and Z. Luo, "A Framework for Examining Mathematics Teacher Knowledge as Used in Error Analysis", For the Learning of Mathematics, vol. 29, no. 3, pp. 22-25, 2009.

[2] S.J. Rushton, "Teaching and learning mathematics through error analysis", Fields Mathematics Education journal, vol. 3, no. 4, pp. 1-12, 2018. https://doi.org/10.1186/s40928-01 8-0009-y.

[3] M. Russell, L.M. O’Dwyer, and H. Miranda, “Diagnosing students' misconceptions in algebra: Results from an experimental pilot study", Behavior Research Methods, vol. 41, no. 2, pp. 414-424, 2009.

[4] P. McGuire, "Using online error analysis items to support preservice teachers' pedagogical content knowledge in mathematics", Contemporary Issues in Technology and Teacher Education, vol. 13, no. 3, pp. 207-218, 2013.

[5] S.W.D. Pomalato, L. Ili, B.A. Ningsi, Fadhilaturrahmi, A.T. Hasibuan, and K.H. Primayan, "Student Error Analysis in Solving Mathematical Problems", Universal Journal of Educational Research, vol. 8, no. 11, pp. 5183-5187, 2020. https://doi.org/10.13189/ujer.2020.081118.

[6] M. Legutko, “An analysis of students' mathematical errors in the teaching-research process,", In B. Czarnocha (Ed.), Handbook for mathematics teaching: Teacher experiment, A tool for research, pp. 141-152, University of Rzeszów, Poland, 2008.

[7] M. Russell, and J. Masters, "Formative diagnostic assessment in algebra and geometry", American Education Research Association Conference, 2009.

[8] R. Herholdt and I. Sapire, "An error analysis in the early grades mathematics - A learning opportunity?", South African Journal of Childhood Education, vol. 4, no. 1, pp. 42-60, 2014.

[9] L.S. Shulman, "Those who understand: Knowledge growth in teaching", Educational Researcher, vol. 15, no. 2, pp. 4-14, 1986.

[10] M. Brown, M.J. Bossé, and K. Chandler, "Student Errors in Dynamic Mathematical Environments", International Journal for Mathematics Teaching and Learning, vol. 17, no. 1, PP. 1-27, 2016.

[11] C.F. Lai, "Error analysis in mathematics. Behavioral Research \& Teaching”, University of Oregon, USA, 2012.

[12] P. Hudson, and S. Miller, "Designing and Implementing Mathematics Instruction for Students with Diverse Learning Need", Allyn \& Bacon, Boston, 2006.

[13] K. Adu-Gyamfi, M.J. Bossé, and K. Chandler, "Situating student errors: Linguistic-to-algebra translation errors", International Journal for Mathematics Teaching and Learning. Retrieved from http://www.cimt.org.uk/jour nal/bosse6.pdf. 2015

[14] K. Adu-Gyamfi, and M.J. Bossé, "Processes and reasoning in representations of linear functions", International Journal of Science and Mathematics Education, vol. 12, no. 1, pp. 167-192, 2014.

[15] A.K. Morris, J. Hiebert, and S.M. Spitzer, "Mathematical knowledge for teaching in planning and evaluating instruction: What can preservice teachers learn?", Journal for Research in Mathematics Education, vol. 40, no. 5, pp. 491-529, 2009.

[16] R.B. Ashlock, "Error patterns in computation: Using error patterns to improve instruction", Pearson Education, Upper Saddle River, NJ, 2006.

[17] I.D. Beatty, and W.J. Gerace, "Technology-enhanced assessment: A research-based pedagogy for teaching science with classroom response technology", Journal of Science Education and Technology, vol. 18, pp. 146-162. 
2009.

[18] M. Rohmah, and S. Sutiarso, "Analysis Problem Solving in Mathematical Using Theory Newman", Eurasia Journal of Mathematics, Science and Technology Education, vol. 14, no. 2, pp. 671-681, 2018. https://doi.org/10.12973/ejmste/8 0630

[19] N.S.A. Alhassora, M.S. Abu, and A.H. Abdullah, "Newman Error Analysis on Evaluating and Creating Thinking Skills", Man In India, vol. 97, no. 19, pp. 413-427, 2017. https://www.researchgate.net/publication/3 22062647.

[20] A.H. Abdullah, N.L.Z. Abidin, and M. Ali, "Analysis of Students' Errors in Solving Higher Order Thinking Skills (HOTS) Problems for the Topic of Fraction", Asian Social Science, vol. 11, no. 21, pp. 133-142, 2015. http://dx.doi.org/10.5539/ass.v11n21p133.

[21] E. Zakaria, and S.M.B. Maat, "An Exploration of Mathematics Teachers' Reflection on Their Teaching
Practices", Asian Social Science, vol. 6, no. 5, pp. 147-152, 2010.

[22] T.A. Burgess, "A framework for examining teacher knowledge as used in action while teaching statistics", Proceedings of the Seventh International Conference on Teaching Statistics (ICOTS 7), 2006.http://www.stat.auckl and.ac.nz/ iase/publications

[23] H.C. Hill, D.L. Ball, and S.G. Schilling, "Unpacking pedagogical content knowledge: Conceptualizing and measuring teachers' topic-specific knowledge of students", Journal for Research in Mathematics Education, vol. 39, no. 4, pp. 372-400, 2008.

[24] D.A. Sousa, "How the Brain Learns Mathematics", Corwin Press, Thousand Oaks, CA, 2008. https://www.researchgat e.net/publication/322062647

[25] J. Makonye, "Mathematics Learner Error Analysis Protocol", Association for Mathematics Education of South Africa (AMESA), pp. 314-323, 2016. 